\title{
Fostering Remembrance and Reconciliation Through an Arts-Based Response
}

\author{
Jenny Kay Dupuis \\ Independent Consultant \\ Kristen Ferguson \\ Nipissing University
}

\begin{abstract}
This paper presents the results of study about an urban high school in Ontario that performed a stage play that portrayed the legacy of the Indian residential schools in Canada. We wanted to know the impact this arts-based response had on teachers and students. From the data that we obtained from focus groups, we identify four learning outcomes of the legacy project: reflection on knowledge and identity; fact-finding through the processes of respecting memory; using the arts to remember; and broadening perspectives: remembrance (memory), reconciliation, and memorialization. Our research can assist educators and researchers to implement an arts-based model that honours and respects residential school survivors and their families.
\end{abstract}

Keywords: residential schools; reconciliation; drama education; arts education; genocide studies

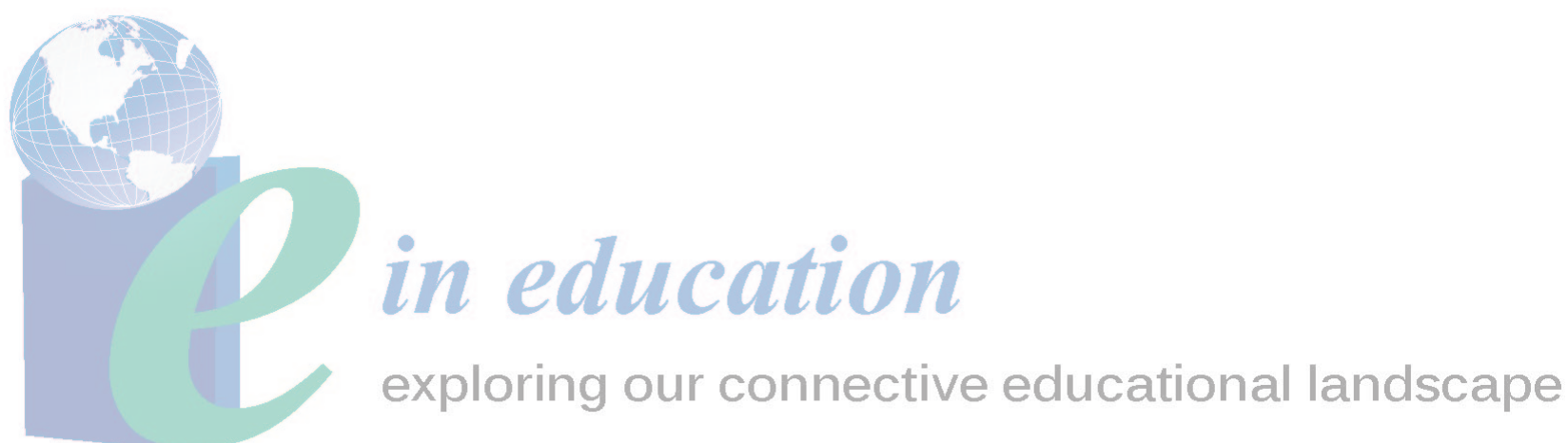




\section{Fostering Remembrance and Reconciliation Through an Arts-Based Response}

"We offer this [play] as... an act of remembrance, an act of continuing being able to talk and heal."

-Teacher in the study

In 2013, an urban public school in Ontario performed a stage play that portrayed the legacy of the Indian residential schools in Canada. High school teachers and students worked together to identify authentic, accurate, and culturally appropriate resources, to listen to survivor stories, to research historical documents, and to visit a former residential school. The information gathered was used to generate an arts-based response, a collectively written play, to engage and educate schools, families, and community members about remembrance and reconciliation of the history and effects of Indian residential schools.

According to Ontario's First Nation, Métis and Inuit Education Policy Framework (Ontario Ministry of Education, 2007) there still exists "a lack of understanding within schools and school boards of First Nation, Métis, and Inuit cultures, histories, and perspectives,” (p. 6) including a limited understanding of the "First Nations perspective on the school system, which has been strongly affected by residential school experiences and has resulted in intergenerational mistrust of the education system" (p. 6). Since the introduction of the policy framework in 2007, limited research has been conducted in Ontario that investigates the topic of reconciliation for the past and present effects of Indian residential schools. According to the Truth and Reconciliation Commission of Canada (2015a):

Reconciliation is about establishing and maintaining a mutually respectful relationship between Aboriginal and non-Aboriginal peoples in this country. In order for that to happen, there has to be awareness of the past, acknowledgement of the harm that has been inflicted, atonement for the causes, and action to change behaviour. (n.p)

Remembrance and memory are thus important concepts related to reconciliation. As Regan (2010) states:

For survivors remembering residential school experiences gives rise to a host of negative emotions involving multiple losses_of self, family, community, language, and culture, along with the devastating intergenerational effects of abuse. At the same time, such remembering can also invoke healing memories of courage, strength, and cultural resilience in the face of extreme adversity and its aftermath. (p. 176)

Not only are these memories significant for survivors, but for all Canadians. Regan (2010) reminds us that while "Canadians might agree in principle that, as a country, we must learn from our past so that history does not repeat itself, most of us 'fail to connect the dots' between this problematic past and current attitudes and policies” (p. 178).

We concur with the TRC (2015a), that in order to reconcile, we must remember. Therefore, in this paper, we explore using the arts, drama specifically, as a form of remembrance and as an act of reconciliation for the history and effects of Indian residential schools in Canada. 


\section{Purpose of the Research}

We feel that remembrance has the potential to play a powerful role in reconciliation. We wanted to add to the scant literature exploring the teaching and learning in schools about the remembrance and reconciliation of Canadian Indian residential schools. Our research focuses on a 2013 production of an Ontario high school stage play about the legacy of Indian residential schools in Canada. The research question guiding our study is: What are the significant learning outcomes for students and teachers of an arts-based reconciliation project about Canadian Indian Residential Schools?

\section{The Legacy Project}

The purpose of the Legacy Project was for staff and students to learn together about the legacy of the Indian residential school system. Theatre was chosen as a medium for the project because it allowed the students to take time to learn about the history and then later use that information to demonstrate their understanding by writing a play. The secondary school is located in a large urban centre in Ontario and its student population consists of Indigenous and non-Indigenous students. The project was supported by a grant received from the Ministry of Education, Aboriginal Education Office to align with the Ontario First Nation, Métis, and Inuit Education Policy Framework (Ontario Ministry of Education, 2007). Indigenous and non-Indigenous students from Grades 9 - 12 who registered were eligible to receive credits for their participation in the project. Students who were involved in the writing of the play were eligible to receive the dual credits, Drama, Grade 11/12, University/College Preparation (ADA3M/3U) and Writer's Craft, Grade 12, University Preparation (EWC4U). Senior level music composition students (AMC4M) received credit for composing original music. For the play, teachers were assigned to the courses based on their subject specialization. The project manager, a teaching coordinator, was assigned to teach two of the courses and manage the organization of the project at the school level. In total three teachers and approximately 53 students participated in project.

\section{The Play}

The final product was a play that was approximately one hour in length. The play was a form of ethnodrama (Saldaña, 2005). According to Saldaña (2005), an ethnodrama is a play that is composed of "dramatized, significant selections of narrative collected through interviews, participant observation, field notes, journal entries, and/or print and media artifacts such as diaries, television broadcasts, newspaper articles, and court proceedings” (p. 2). For the legacy project, teachers and students worked to identify historically accurate and culturally respectful resources, listen to survivor stories, research historical documents, and visit one of Canada's last standing former residential schools.

The students created a live theatre performance with the characters in the play portraying both Indigenous students and non-Indigenous staff members (i.e. teachers, nuns, priests, etc.). Students enrolled in the Drama and Writer's Craft dual-credits course wrote the script. There was no speaking in the play. Instead, the audience used the visual images and music to create meaning. Original music was composed and performed by students to match the mood and action of the play. Music took the place of a script (the words) to communicate the general loss of rich and diverse Indigenous languages and knowledge. Strong imagery and symbolism were used throughout, including a massive tree, a red hooded sweater, and handprints. The symbols selected were intended to be respectful to the survivors and their families. The intention was to 
avoid potential triggers by not focusing too much on the abuse or other triggering events that might have taken place at residential school. For instance, a large, overpowering tree was the focal point of the stage. The tree symbolized the basic concepts of time, roots, growth, and stability. The tree itself was inspired by one of the teacher's first visit to a former residential school:

Long before the idea of the play, I walked out back, was drawn to the tree (dying) and when I touched it I was struck by how the place and stories and experiences and truth could not be left to die. That the years in that tree's life likely began before a school was there and ended after it was closed....and the truth could not be left to die.

Coloured sweaters were used as metaphors; for example, one of the female students wore a red hooded sweater, which symbolized Indigenous identity, language, and culture. The red sweatshirt was symbolically taken from a young girl when she arrived at the school. The other children later returned it to her-an indication of restoration and revitalization of culture. Several others forms of imagery were used including handprints scattered throughout one of the scenes to represent abuse. In one instance, when a boy comes to help a girl, he also has handprints on him, symbolizing that the children were abused. To further demonstrate this, when the students at the end of the play left the stage, the stories of the survivors, were displayed through a series of archival photographs of residential school students and schools streamed across a large backdrop.

\section{Perspectives on Reconciliation}

From 1892 to 1996 there were approximately 130 government and church run Indian residential schools in Canada (Chansonneuve, 2005). There were over 150,000 First Nations, Métis, and Inuit children who were removed from their home communities and forced to attend government-run schools (Miller, 1996). The intent was to assimilate all Indigenous children into mainstream Canadian society by not allowing them to speak their native language or practice their traditions (Chansonneuve, 2005). As the Truth and Reconciliation Commission of Canada (TRC, 2012) includes on the cover page of their book, They Came for the Children, this was a purposeful attempt by the Canadian government to assimilate Indigenous peoples. Hector Langevin, the Public Works Minister of Canada said in 1883, "In order to educate the children properly we must separate them from their families. Some people may say that this is hard but if we want to civilize them we must do that" (as cited in TRC, 2012, cover page). Children in residential schools often faced severe forms of punishment and/or abuse (TRC, 2012). Instead of traditional language and culture, Indigenous children were forced to adopt either the English or French language in addition to Christianity and Canadian customs (TRC, 2012).

Finding a clear direction on how reconciliation can be realized is a struggle since there is limited scholarly literature available on the topic (Burridge, 2006). At the same time, in moving forward, it is essential that First Nation, Métis, and Inuit students not only feel engaged, but also that they see themselves and their cultures reflected in the curriculum and the school community (Ontario Ministry of Education, 2007). The notion of reconciliation is one of the most significant challenges in the world today (Ahluwalia et al., 2012).

In moving forward towards reconciliation, the Council of Ministers of Education (CMEC) has endorsed a national Indigenous education strategy that encourages school districts 
to integrate new curriculum that focuses on the history of the residential school system that will allow all students to gain an understanding of how it affected the country (CMEC, n.d.). The Honourable Eva Aariak, Premier and Ministry of Education for Nunavut acknowledged, "It is no longer acceptable for Canadians to complete their formal education unaware of this dark change in our country's history” (CMEC, 2013, n.p.). In their Calls to Action, the TRC (2015b) includes the following:

62. We call upon the federal, provincial, and territorial governments, in consultation and collaboration with Survivors, Aboriginal peoples, and educators, to:

i. Make age-appropriate curriculum on residential schools, Treaties, and Aboriginal peoples' historical and contemporary contributions to Canada a mandatory education requirement for Kindergarten to Grade Twelve students.

ii. Provide the necessary funding to post-secondary institutions to educate teachers on how to integrate Indigenous knowledge and teaching methods into classrooms.

iii. Provide the necessary funding to Aboriginal schools to utilize Indigenous knowledge and teaching methods in classrooms.

iv. Establish senior-level positions in government at the assistant deputy minister level or higher dedicated to Aboriginal content in education.

63. We call upon the Council of Ministers of Education, Canada to maintain an annual commitment to Aboriginal education issues, including:

i. Developing and implementing Kindergarten to Grade Twelve curriculum and learning resources on Aboriginal peoples in Canadian history, and the history and legacy of residential schools.

ii. Sharing information and best practices on teaching curriculum related to residential schools and Aboriginal history.

iii. Building student capacity for intercultural understanding, empathy, and mutual respect.

iv. Identifying teacher-training needs relating to the above. (p. 7)

Learning about the history and legacy of residential schools is a vital step towards reconciliation. As Bell (1997) states, "Knowledge of history helps us to trace the patterns that constitute oppression over time and enable[s] us to see the longstanding grievances of different groups in our society" and "it offers hope as well as the evidence that oppressive circumstances can change through the efforts of human actors" (p. 6).

Remembrance and reconciliation are linked because "learning about the history of the residential schools can contribute to the collective healing process and strengthen the fabric of communities across the country" (CMEC, 2013, n. p.). It is through continued research in the field that additional knowledge will help to advance programming about Indigenous issues for all. 


\section{The Arts and Reconciliation}

Arts-based research provides perspectives, rather than universals truths. According to Taylor (2006), "by embracing the artistic medium as a way of re-envisioning the data, researchers acknowledge that qualitative research is a human-situated act, and that no one grand narrative should hold priority" (p. 12). Like art itself, arts-based research is interpreted by the individual and "in heightening the reader or audience member's ability to construct their own interpretation of the data, there is promotion of the individual's capacity for freedom” (Taylor, 2006, p. 12). In a project dealing with such an important and sensitive topic as Indian residential schools, drama also provides an opportunity for reflexivity in performance, which can provoke a critical consciousness in the audience (Neelands, 2006). Drama can be a catalyst for critical thinking and reflection for the audience and its participants.

While there is a body of research that explores using drama as means of remembrance for other histories like the Holocaust (e.g. Rosler, 2008; Schumacher, 1998; Zatzman, 1999, 2005), there is limited research available about arts-based projects that merge the act of remembrance and reconciliation for the history and effects of Indian residential schools. In terms of using theatre, after an extensive literature review, we found only the work completed by England (2002, 2004), which explores drama as a mode of response to residential schools. Drama is a useful medium to explore topics such as history and memories because it "facilitates transformational experiences for students and teachers alike, ones that bring new understandings of the world and our ability to express ourselves in relation to it and each other” (England, 2002, p. 18). England (2002) outlines the pedagogical process to make learning meaningful for students learning about the richness of the memories of the Indigenous peoples and the residential school system. In so doing, England describes a unit plan that merges drama and historical discourses. Students in England's research were given the opportunity to engage with survivor testimonies, journal, and create drama performances. England's (2004) Master's thesis demonstrates that using drama as a mode of response appears to increase a sense of critical awareness among students, and students were able to express themselves about issues of those in marginalized communities, including survivors of residential schools. While exploring sensitive topics in the classroom can be difficult, England (2004) believes that teaching for memory and social change are crucial. Despite feelings of discomfort or unease, "We as educators must be willing to delve into murky, contested territories, knowing that the work might be difficult and knowing too that it might generate more questions than answers” (England, 2004, pp. 120 - 121).

\section{Theoretical Framework: Social Constructivism and Drama}

To ground this study, we use the theories of constructivism and social constructivism to describe the learning processes. Constructivism is based on the tenant that students construct their own knowledge and that "each individual constructs his or her own understanding of his or her unique world" (Gibson, 2009, p. 25). As Maxim (2014) states, "when we talk about constructivism, we refer not only to what the children know but to how they acquire and organize information in their minds” (p. 131).

Constructivist theorist Jean Piaget (1972/1973) proposes that students have anchoring concepts or schemas - this is the student's background knowledge. Any new material learned is then integrated into a student's existing schema (assimilation), or if the knowledge is in conflict 
with the existing schema, cognitive constructs must be rearranged or new constructs created (accommodation) (Piaget, 1972/1973).

Vygotsky (1978) presents another form of constructivism, social constructivism, whereby interaction with others is key to advancing learning. By working with an adult or "more capable peer," students learn by completing tasks that are too difficult for them to do on their own (Vygotsky, 1978, p. 86). The social component of learning is crucial for Vygostsky (1978); he writes, "Human learning presupposes a specific social nature and a process by which children grow into the intellectual life of those around them” (p. 89).

Based on a constructivist approach, learning is then "a process that involves the interaction of past experience, personal intentions, and new experience” (Gibson, 2009, p. 25). Knowledge and learning is, therefore, not taught but rather constructed by and in the unique individual. Learning should not be a passive activity; learning should be active and meaningful as students create their own knowledge with the assistance of an adult or more capable peer.

Gibson (2009) summarizes the literature and identifies five key principles of social constructivism for learning:

- Recognizing importance of social context,

- Actively engaging learners,

- Incorporating prior learning,

- Supporting individual knowledge construction, and

- Reflecting on learning. (p. 31)

The first four principles are clearly related to the work of Piaget (1972/1973) and Vygotsky (1978). But for the last principle, reflecting on learning, Gibson (2009) draws on the importance of reflection. Dewey (1933) writes that reflective thinking is when a person looks back on an experience, and considers it sequence and its consequence. Gibson argues that this reflective thinking is key to social constructivist learning because "it gives students opportunities to talk and write about their learning means to them, how they care about it, and how it is connected to their lives and the knowledge that they have" (p. 36). Reflection, then, allows students to think about their constructed knowledge and to make learning intrapersonal (Gibson, 2009).

Because of the active and participatory nature of the arts, there is a natural link between constructivist learning theory and the arts. Learning is not passive in the arts; students learn and construct their own knowledge as they create, experience, and express. Wright (2007) argues that drama is solidly grounded in social constructivism:

Drama is an experience in which individuals create and respond to a network of relationships ... Associated with these networks are understandings, energies and experiences that participants bring to, meet within and take away from encounters with drama. (p. 45)

Drama fits the principles of social constructivism outlined by Gibson (2009): drama is a creative, social, and an active process wherein students use their prior knowledge to create their own unique understandings. As Wright (2007) says, “[drama] identifies the student as the constructor of meaning as a consequence of her participation in a sensual embodied experience” (p. 47). The social aspect in constructing knowledge is important in drama: "The drama community (or group 
or cast or class) as a collection of individual constructors of meaning requires, by circumstance, to negotiate their feelings and rationality-their embodiment” (Wright, 2007, p. 47). Like Gibson (2009), Wright argues that reflection is a key part of social constructivism in drama. He writes that the experience of drama goes beyond the performance and the dramatic experience “demands reflection” (p. 48) because so much can be taken away as learning in a dramatic experience.

\section{Methodology}

As previously mentioned, the purpose of this study is to explore the significant learning outcomes for students and teachers from an arts-based reconciliation project about Canadian Indian residential schools. It is important to note that our study was conducted after the play was performed and the project was completed. Jenny, the first author of the paper, acted as a consultant for the legacy project. Kristen, the second author, had no involvement in creation or performance of the legacy project. Our methods are explained below.

\section{Participants}

The participants in our study were non-Indigenous teachers and non-Indigenous and Indigenous students who were actively involved in the creation of the legacy project in a school district in Ontario, Canada in 2013. The project leaders were three teachers of non-Indigenous descent who had specialized training in the areas of drama, theatre, and music. In the original project, there were three Indigenous students and 50 non-Indigenous students who participated. Two of the three Indigenous students discussed having family members who attended residential schools. Three teachers and nine students (one of whom was Indigenous) participated in the focus groups, the data collection for this study.

\section{Data Collection}

We decided to use qualitative research instead of quantitative research because qualitative research seeks "to better understand human behaviour and experience" (Bogdan \& Biklen, 1998, p. 38). We used focus groups to gain valuable insights into the perceptions, attitudes and values of the students and teachers who participated in the project (Morgan, 1998). Focus groups are a useful tool for research, as the group dynamics create a synergy and allow for interaction and responses among participants (Krueger \& Casey, 2009). We also felt that the group setting of a focus group provides a less intimidating and more comfortable setting for high school students than interviews. The first author, Jenny, conducted two focus groups: one group for the students and one for the teachers. For the teacher focus group, three teachers agreed to participate. For the student focus group, nine students agreed to participate. Several of the students had graduated or relocated schools by the time of the data collection, spring 2014. During each focus group, Jenny asked nine questions regarding the project and their experiences and perspectives on reconciliation (see Appendix A). Each focus group lasted approximately appropriately two hours. The same questions were used for both the student and teacher focus group. Focus groups were audio recorded and transcribed by Jenny. The transcripts were shared with the teachers and students to ensure trustworthiness of the data.

\section{Data Analysis}

We conducted the analysis inductively based on themes that emerged from the data. We began by sorting the data from focus group transcripts by interview question. We then 
individually read the data sorted by interview questions and independently identified themes and patterns that emerged (Bogden \& Biklen, 1998). We then discussed and compared our patterns and themes and agreed on five overall learning outcomes. Having multiple researchers explore the data and come to a consensus helps to increase the reliability of the data analysis (Patton, 1990). We then grouped the data together by learning outcome using Microsoft Word.

\section{Results and Discussion}

We identified four key themes that stood out as significant learning outcomes about how an artsbased school and community reconciliation project about Canadian Indian residential schools impacted teachers and students:

- Reflection on knowledge and identity,

- fact-finding through the processes of respecting memory,

- using the arts to remember, and

- broadening perspectives: remembrance (memory), reconciliation, and memorialization.

\section{Reflection on Knowledge and Identity}

When the teachers started working on the on the project, they felt that their content knowledge about Indigenous peoples was limited to non-existent. During the focus group, teachers stated that it was through this project that they learned about the legacy of Canada's residential school system. Although the teachers in the project had studied other genocides, mass atrocities, and human rights violations from other parts of the world, at no time did they learn about what happened in their own country. At the outset of the project, teachers felt that they would have a steep learning curve without a certain level of expertise in the field of Indigenous studies fused with Indigenous community-based knowledge. The teachers stated that they had a responsibility to themselves (as learners) to take the time to understand what they did not know and ensure that everyone who participated was fully supported in their learning. The teachers believed that their goal was to raise awareness about the legacy of the residential school system even though they felt that introducing a new, sensitive topic to the students (and later the community) could potentially be overwhelming, emotionally daunting, and potentially damaging for all. One of the teachers explained:

The responsibility piece is probably the most daunting and the greatest. It's a feeling, a responsibility as a teacher to students in introducing a topic in a way that recognizes that there is going to be a great deal of despair. Where do you find the hope when you are studying something like this? ...How do we then take this very disparaging topic and present it in a way that doesn't add damage to what's been done.

The teachers realized that they needed to work slowly and respectfully in partnership with the students and the local Indigenous community while being prepared to frequently ask questions, educate themselves, and connect with local experts (e.g. residential school survivors and their families and the former residential school). As one teacher said:

In starting with understanding the truths and the history and the stories, we had an opportunity to speak with survivors and spend time at the residential school in the 
library and to walk the ground to tour the building to see many places that many people do not get to see. It was always a constant reminder. As we were going through the project, one of the teachers was there leading us by being our moral compass, making sure that we were staying true to what this was.

Students, like their teachers, did not have much background knowledge about residential schools. Several students expressed that they knew nothing about the history of residential schools, and if they did, they knew very little about what actually happened behind the walls. According to one student, "I knew a tiny bit about it because we touched on it in previous history classes. I knew about residential schools. I didn't know what happened inside of them. I thought they were just normal schools." Another student said, "It took a little bit before it clicked in that what happened in residential schools was genocide itself. It just fascinated me that Canada would do something like this." For another student, the story of the residential school system was slightly familiar:

My mom had a friend; she was a family friend for a long time. She didn't tell me this herself, but my mom told me that she went to a residential school and [she and] her sister were sent away and were split up. One went to residential school and the other was taken by CAS and sent away to the States and adopted.

Working through the emotions that came with this new learning about Canada's past was a challenge for most students. As one student explained, it "hits you like a ton of bricks, like why do you have these feelings? It's [residential schooling] not right and learning about it is going to get all emotional." Another student reflected, "I had no clue what had gone on in these schools and I was definitely shocked of what happened. So you have to be prepared for that; it is very emotional. You have to be emotionally prepared for anything." This new knowledge that Indigenous people's culture was taken away and almost destroyed through processes of assimilation is what appeared to motivate most of the students to want to do something about it. "We are living in Canada and it is something we should find out about ... I should know about the past and what happened," stressed one of the students. Another student explained that despite the heavy emotions, "we want to show healing."

For some students, this new knowledge of what happened at residential schools coupled with being involved in the project was challenging as they struggled with their own identity and felt conflicted when dealing with emotions of guilt and what had taken place. One student said:

I almost backed out. I tried several times to talk to the teachers about getting out of the course just because I didn't feel....It was my background that had done these things to these people. I didn't feel like I had a right to be a part of the healing process...It took me a long time to feel like I was in the right place to add what I had to say to the project.

Consequently, some students felt conflicted, questioning if they were the ones who should be telling the story: "I thought it was not my responsibility, not being Aboriginal in any way...I felt like I didn’t have anything to say, or anything to do with it since it didn’t happen to me.”

The students who identified as being of non-Indigenous ancestry generally struggled with managing their own emotions once they started to think about what their ancestors must have known. Many of the non-Indigenous students felt like they wanted to apologize for what their 
ancestors had done; the students wanted to make things right again. As one student said, "I felt it was my responsibility" to let people know what happened in residential schools. There was only one student in the group who self-identified as having Indigenous ancestry, and he discussed how his prior experiences participating in Indigenous ceremonies made him feel inspired to participate in the project: "I related it to the fact that I was distantly related to some of the people that could have gone through this... that kind of hit home for me."

Some students stated that they were somewhat concerned about the sensitivity of the topic and the possibility that Indigenous people were perhaps still "angry." But the students stated during the focus group that they agreed as a collective that they would seek to learn the truth about the history of the residential schools and meet Indigenous people where they were at: "I had personal challenges trying to address the sensitivity and the emotional responsibility ... it was to accept that Aboriginal peoples might still be angry and you have to accept that," stated one of the students. Working together as a team helped to overcome the emotion and identity conflicts that the students and teachers experienced. As one student said, "We worked as a group of people who overcame it [the emotion] by working together and telling the story."

\section{Fact-Finding Through the Process of Respecting Memory}

The teachers and students explained during the focus groups that they made great efforts to follow a learning process that was respectful to the history by engaging with the local Indigenous community's lived experiences. In so doing, the teachers turned to members of the Indigenous community (e.g. residential school survivors, the school board's Indigenous liaison, and individuals who offered educational tours at a former residential school) to explain their ideas, seek their approval, and ask for guidance and ongoing support. One of teachers stated, "when the reception [from the Indigenous community] kept being yes, and yes, and yes, we felt welcomed. That is really a huge step because it could get messy and uncomfortable and we could make mistakes." The teachers felt it was essential to have the community's approval and support since they felt they were of-Indigenous ancestry and it was "not their story to tell." It was important for them to find a way to ensure that Indigenous community voices be heard and conversations take place. They didn't want to add more damage or cause upset. One of the teachers explained,

Making sure that community voices can be heard and how do we then take this very disparaging topic and present it in a way that doesn't add damage to what's been done? How do you find a way that moves things forward or for the first time opens up conversations between people that have not had conversation beforemaking it safe for students to do so and find a vocabulary, to find a language, to find a way to ask questions and how do you then shape that and present it in a way that will extend those conversations and open it up more to questions and more dialogues happening in our communities and throughout our students lives.

The learning process was important for teachers, just as much as the finished drama piece. As one teacher explained, "I think one of the most important ways that truth was honoured [was that] legacy was honoured through the process.” They listened to the Prime Minister's address and apology, read Indigenous-rich literature, reviewed historical images, and engaged with a network of individuals who were committed to support them in staying true to retelling the history. 
In talking about and creating the play, teachers frequently used the phrase, "honouring the truth." Teachers were cognizant that these were peoples lived stories and lives. One teacher recommended that teachers teaching about residential schools need to "be truthful, drop your agenda." Another said that teachers need to "remain honest and truthful, honour those stories that you are finding, honour the people of the stories that they belong to." Respect for Indigenous peoples and the survivors of residential schools was key for teachers when learning about residential schools and creating the play.

The students felt honouring the truth and respecting the survivors was paramount. One student explained, when learning about residential schools, "you have to open yourself up and be ready to learn and be sensitive" and another said, "Try to learn about it from the [the survivors] but respect them as well." The students also noted that they did not want to offend anyone by pretending to be someone they were not. They simply wanted to tell the story well:

We had to take into consideration that we were not them and we did not go through what they went through. We had to tell the story the best way we could to actually let people know that this happened.

Another student pointed out that they had to consider "not making it about us and making it about them." It was not their story, so they felt that respect had to be shown at all times. It was the visit to the former residential school that struck them most. It gave them an opportunity to see for themselves how Indigenous children were separated from their home communities, to hear the stories from a survivor's point of view, to see where the residential school students had lived, and to look at the bricks on the back of the building that were scrawled with messages. During the focus group session, it was evident that student learning of the history of residential schools was deep and inspired introspection. As one student reflected:

I kind of felt bad as a human because I got to live a childhood and got to live free and their childhood was stripped away, their identity, and it was really just harsh and emotional and they didn’t get the freedom that we do and it was horrible.

\section{Using the Arts to Remember}

During the focus group session, teachers pointed out that works of art (e.g., theatre, music, etc.) can be acts of reconciliation because they encourage the audience to talk and share stories so that they can all heal. The teachers believed that the arts have a "didactic quality." They wanted the audience to recognize and remember what happened. The arts provided a medium to share the truths they had learned about residential school. As one teacher noted:

It was amazing to see that the audience members and the actors on stage just disappeared and people were so engaged with the show that they felt that they were just experiencing these things for themselves. And that is what [art] does; it draws us in and makes us experience things so that we can learn from them.

Making connections through the arts facilitated a way to honour the survivors and work towards reconciliation. As one teacher said:

The way the story was presented, it opened it up with the idea that we can reconcile through our local community. Although it was challenging to convey the story 
through the arts, it clearly demonstrated that music, symbolism, and imagery combined together can be truly a universal language.

The absence of words in the play was a very powerful experience for students and teachers. As one student explained, "rather than speaking, we used our bodies and facial expression....It sent a better message...a lot of people understood even without a single word spoken." Another student said, "It pushed us to see what happened in silence and pushed us to explore and experience what happened without words or what happens without speaking." And another student pointed out: "By people acting on stage it just makes it easier to understand by seeing what some of these kids might have gone through [rather] than hear them; they get to physically see it.” She continued:

A lot of us are not good at English or other subjects, and we are not good at writing, but when we act with our bodies we can express so much more and we can put so much more emotion behind it [rather] than just reading something out loud. It made a bigger impact for everybody.

Silence can be powerful. As one teacher stated:

We often lose those amazing moments in our lives because we want noise to happen and instead it pushed us to see what happened in silence and pushed us to explore and experience what happened without words or what happens without speaking. For the audience-the students did not have a voice that made things even stronger.

Original music composition and visual imagery were used in place of spoken words (vocals) to express main themes, places, and key moments. One teacher reflected:

I think the idea of the imagery and music that we used made it relevant to any generation because we weren't caught up in the words or other things, and it tied into the idea of the loss of the voice in the culture and it was replaced with the idea we could read and hear what they were doing through the music and actions.

Music was composed in such a way that students and teachers were able to move past the symbolism alone and to strive to convey emotions. As one student explained:

We stuck to some major themes in the music that we played. The absence of words/vocals imparted emotional responses to the listener to show key themes of the narrative story through the introduction of contrasting styles of music like religious hymns, military-esque marches, and Aboriginal drum styles. We had one thing for the Taker [a large, mysterious figure who represented the church]; we had some things for the red sweater, the good moments, [and] the bad moments.

By integrating Western Christian hymns with Indigenous drumming, the theme of reconciliation was enhanced. One teacher stated that music was also used to convey places and key moments: "Hymns [were used] to help feel like it was in the church... and the different drumming styles to help bring back and reconcile what happened to help enrich the performance.”

Removing the words also allowed the audience, who may have been from any linguistic background, to interpret the story. One teacher explained: 
I think also it was a choice of not having the words. It opens it up to a lot more people that they didn't have to speak English. It was the way the story was presented it opened it up with the idea that we can reconcile through our local community but it came to be a larger more global form of reconciliation and because there is nothing [no words]. We are removing another barrier from people experiencing the story and experiencing the history.

One student reflected that having no words allowed for audience interpretation and reflection about Canada's history of residential schools:

I think by using the art-based method, and not having any words, we just gave the people the knowledge they needed... here's what we have done, and we have asked them to take the knowledge and interpret it on their own.

\section{Broadening Perspectives: Remembrance (Memory), Reconciliation, and Memorialization}

At the outset of the project, the teachers and students needed to determine where they stood in terms of reconciliation. This proved a challenge for some, as one teacher said:

The reconciliation part of that was a greater challenge because for me, and I think for each student, [because] they had to figure out where they fit in with reconciliation. What matters most is that you need to understand why you are doing something; otherwise, there is really no point in doing it.

The teachers and students were concerned that many people would continue to not believe the story. According to one student, it was a challenge "that people wouldn't believe what we were saying. It [residential schools] did happen." There was also concern that the true impact of residential schools would not be recognized. Another student explained:

For me, I have a lot of interest in genocide, especially concerning the Holocaust, and to think those people get recognized so much. Not saying it is not important. In Canada, we recognize them so much, what they went through, but people do not realize that here people went through the same thing and it just bothers me in a way because you are blaming the Germans and Hitler for what they have done but in your own country, your government had done the same thing.

But the teachers and students involved in the Legacy Project wanted to stand up and say that "it did happen." According to one teacher, "We need to do our part to reconcile with the fact that we did this, that we are a part of this, and that our country was a part of this, and it's a piece of our history that is very hidden.”

For students, the theme of humanity was important, and that as humans, we are all related. As one student said, "Just knowing how close to home it hits....We are all just families; we are all people. The idea of segregating is wrong." Another student explained, "I felt bad as a human because I got to live a childhood and got to live freely and their childhood stripped away their identity... they didn't get the freedom that we did and it was horrible." "We need to send the message out because issues like this are happening all over the world; we need to remember that we are all humans," said another student. 
Some teachers also felt that the project was an opportunity to be a part of reconciliation and to do something about the injustices of Canada's residential schools. As one teacher explained:

The reconciliation part was what motivated me... down deep the gut instinct was this this was utterly wrong and we hid this and we need to do our part to reconcile with the fact that we did this. That we were a part of this, and that our country was a part of this, and it's a piece of our history that is very hidden.

The message of the play reached beyond the school and community and into the global community via social media outlets (i.e. YouTube, Twitter, etc.) all the way to Europe. It reached a broader audience than what was initially expected. One student stated, "When our teacher told us that a college student in England heard about our project that blew my mind because that means that our work is getting out there and people are going to learn about it.”

At the end of the project, the students and staff were recognized and honoured with braids of sweetgrass by a consultant and an eagle feather by a community member. It was recognition by the greater community that they had done a good job in learning about and sharing the story of the survivors. The teachers and students who participated in the legacy project noted that they will continue to explore ways to learn more about the world around them with a particular focus on Indigenous peoples - their culture, history, and hardships. The arts also proved to be a powerful catalyst for this desire to learn more. "As we came to the end of the project, it became apparent that we still had a lot left to learn,” stated one teacher. This teacher explained:

We came full circle and were able to transform ourselves and our perceptions [our stereotypes]...we were able to transform throughout the process. And we were able to end the project knowing that we have many things we still need to learn and there is still many things that we need to continue to reflect on, but that reflection piece is a big piece of drama-specifically in the arts.

\section{Limitations}

Qualitative research studies can be limited by the number of participants and research sites (Marshall \& Rossman, 1999). This is limited in the number of participants, so we are unable to produce broad-based scientific generalizations. Our study only looked at the responses of the teachers and students who participated in the development of one live theatre performance from a particular area of Ontario. Focus groups have many benefits (Krueger \& Casey, 2009; Morgan, 1998) but some participants may have felt more comfortable speaking to the researchers in an interview setting. Participants may withhold thoughts and ideas in a focus group because they may be concerned about how their comments are perceived by others in the group. Finally, our study is limited in that the data collection was a one-time focus group session, rather than a longitudinal study. Following an art-based project over time could explore a number of themes in an in-depth fashion, including examining learning and attitudinal changes over time.

\section{Suggestions for Future Research}

Despite the study's limitations, the information from our study can offer practical insights for other educators who are seeking out ways to address the topic of reconciliation at the school and community levels. Our study is also a significant contribution to the scant literature about using the arts to explore residential schools, remembrance, and reconciliation. Because there is a recent 
movement (CMEC, n.d.; TRC, 2015b) to integrate the legacy of Canadian residential schools along with aspects of reconciliation into the $\mathrm{K}-12$ curriculum, it is highly recommended that research continue so that rich data can be gathered to help tell a greater story of what Canada's education systems are doing at the present time to remember, reconcile, and memorialize the accounts. We encourage practitioners and researchers to continue to explore remembrance and reconciliation using the arts. We see the Canada Council for the Arts'(2015) recent call for " $\{\mathrm{Re}\}$ conciliation: Articulations Through Artistic Expression of Conciliation and Reconciliation" as an encouraging step and look forward to the explorations of using the arts as a response for reconciliation. We hope there are further support from governments, agencies, universities, colleges, and school boards to support in-class and school projects as well.

\section{Conclusion}

The path towards reconciliation is not easy; however, Indigenous and non-Indigenous people have a vital role to play. In this study, telling the truth was a first step. The teachers and students were prepared to tell the truth-to accept full responsibility, including the challenges that come along with truth telling about a sensitive and traumatic topic. Throughout human history, it is evident errors are often repeated and feelings of mistrust and disappointment grow. Stepping forward and identifying a way to share the legacy of Indian residential schools with the greater community can help to promote the concept of remembrance while building understanding and healing. For the teachers and students in our study, they had mainly a gut instinct that they had to accept the responsibility to tell the truth about a long period of history that was hidden and not talked about for so many years.

As England (2004) also reported, our study finds that the process of using an arts-based response to Canada's residential schools is not an easy task for teachers or students. Some of the challenges our participants struggled with were as follows:

- Recognizing and accepting that it was not their story to tell,

- dealing with finding answers related to copyright (who owns the story?),

- trying to figure out where they fit in,

- dealing with emotions of guilt,

- recognizing the challenges of knowing who to talk to and how to be politically correct,

- understanding how students self-identify and see themselves,

- understanding the role of the survivors and their story,

- understanding Indigenous culture, and

- understanding how to move throughout in a way that connects with the Indigenous community.

Additionally, it was a huge responsibility for staff and students to put together a live theatre performance while being faced with so many challenges. In their minds, there was a sense of urgency to construct a remembrance piece that could be shared with the school and greater community. The teachers realized that the topic of residential schools was still sensitive and challenging, so they were mindful that they needed to give the students adequate time to investigate and explore the areas they were interested in while honouring the truth. Despite these challenges, the deep learning that occurred from this arts-based project was well worth the struggles. In creating a remembrance project, the students also created their own memories. As one student said, "Be prepared because when you start to learn about this stuff, you get it, and it 
will stick to you forever." Reconciliation is a complex concept; as one teacher in our study said, "Each student had to figure out where they fit in with reconciliation."

Our work also shows that the drama was an opportunity for social constructivist learning (Gibson, 2009; Wright, 2007). In creating a performance about residential schools, teachers and students also created a supportive social network as each participant constructed their individual understanding and learning about the history and impact of residential schools and the concept of reconciliation. As each teacher and student had different background experiences and schemas, the dramatic experience provided an opportunity for each person to learn about and grow as a result of their participation in the drama in individual ways. Participating in both the drama and our research study allowed students and teachers to reflect on their new learning, understandings, and attitudes. As the results section indicates, the learning was introspective and a personal journey for each participant.

Based on our study, we identify five considerations for educators and students who would like to address remembrance and reconciliation through the arts:

- Encourage all students to explore what sparks their curiosity.

- Determine ways to find hope in dealing with a sensitive topic without adding to the existing damage by making certain that it is being explored in a respectful and responsible way.

- Take time to identify local community resources (e.g. talk/partner with Indigenous community members; identify local spaces/places, etc.).

- Honour the truth by regularly going back to the resources and checking the facts.

- Recognize it is not your story to tell. Ask yourself, "How you will respect Indigenous community voices? How will the project give back to the greater community?”

Like the TRC's (2015b) Calls to Action, we encourage schools and school systems to integrate remembrance and reconciliation for Canada's Indian residential schools. We advise that remembrance and reconciliation must be approached through a multi-layered process that requires taking the time to understand past histories, acknowledging truths and learning to do the right thing. 


\section{References}

Ahluwalia, P., Atkinson, S., Bishop, P., Christie, P., Hattam, R. , \& Matthews, J. (2012). Reconciliation and pedagogy: Postcolonial politics. New York, NY: Routledge.

Bell, L. A. (1997). Theoretical foundation for social justice education. In M. Adams, L. A. Bell, \& P. Griffin (Eds.), Teaching for diversity and social justice: A sourcebook ( $2^{\text {nd }}$ ed., pp.1 - 14). New York, NY: Routledge.

Bogdan, R. C., \& Biklen, S. K. (1998). Qualitative research for education: An introduction to theory and methods (3rd ed.). Boston, MA: Allyn and Bacon.

Burridge, N. (2006). Meanings of reconciliation in the school context. Australian Journal of Indigenous Education, 35, 68 - 77. doi:10.1017/S132601110000418X

Canada Council for the Arts. (2015). \{Re\}conciliation: Articulations through artistic expression of conciliation and reconciliation. Retrieved from http://canadacouncil.ca/ /media/files/misc/reconciliation-call-for-proposals-05-15.pdf

Chansonneuve, D. (2005). Reclaiming connections: Understanding residential school trauma among Aboriginal people. Ottawa, ON: Aboriginal Healing Foundation.

Council of Ministers of Education, Canada (CMEC). (2013, July). First CMEC meeting in Nunavut tackles legacy of residential schools. Retrieved from http://www.cmec.ca/278/Press-Releases/Ministers-Call-for-More-Innovation-andExpanded-Opportunities-as-Education-Systems-Look-to-the-Future.html?id_article=626

Council of Ministers of Education, Canada (CMEC). (n.d.). CMEC Aboriginal Education Plan 2015-2017. Retrieved from http://cmec.ca/532/Programs-and-Initiatives/AboriginalEducation/CMEC-Aboriginal-Education-Plan-2015-2017/index.html

Dewey, J. (1933). How we think. Chicago, IL: Henry Regnery.

England, J. (2002). Understanding and representing memory through drama: A lesson plan in three acts. Stage of the Art, 14(4), 18 - 22.

England, J. (2004). Histories of forgetting, geographies of remembering: Exploring processes of witnesses and performing in senior secondary humanities classrooms (Unpublished master's thesis). University of British Columbia, Canada. Retrieved from https://circle.ubc.ca/bitstream/handle/2429/15234/ubc_2004-0208.pdf?sequence=1

Gibson, S. E. (2009). Teaching social studies in elementary schools: A social constructivist approach. Toronto, ON: Nelson.

Krueger, R. A., \& Casey, M. A. (2009). Focus groups: A practical guide for applied research (4th ed.). Thousand Oaks, CA: Sage.

Marshall, C., \& Rossman, G. B. (1990). Designing qualitative research (3rd ed.). Thousand Oaks, CA: Sage.

Maxim, G. W. (2014). Dynamic social studies for constructivist classrooms (10 ${ }^{\text {th }}$ ed.). Upper Saddle River, NJ: Pearson. 
Miller, J. R. (1996). Shingwauk's vision: A history of the residential school system. Toronto, ON: University of Toronto Press.

Morgan, D. L. (1998). Focus groups as qualitative research. Thousand Oaks, CA: Sage.

Neelands, J. (2006). Re-imagining the reflective practitioner: Towards a philosophy of critical praxis. In J. Ackroyd (Ed.), Research methodologies for drama education (pp. 1 - 12). Stoke on Trenk, UK: Trentham Books.

Ontario Ministry of Education. (2007). Ontario First Nation, Métis, and Inuit education policy framework. Retrieved from http://www.edu.gov.on.ca/eng/aboriginal/fnmiFramework.pdf

Patton, M. Q. (1990). Qualitative evaluation and research methods (2nd ed.). Newbury Park, CA: Sage.

Piaget, J. (1973). The child and reality: Problems of genetic psychology. (A. Rosin, Trans.). New York, NY: Grossman. (Original work published in 1972)

Regan, P. (2010). Unsettling the settler within: Indian residential schools, truth telling, and reconciliation in Canada. Vancouver, BC: UBC Press.

Rosler, B. (2008). Process drama in one fifth-grade social studies class. The Social Studies, 99(6), 265 - 272.

Saldaña, J. (2005). Ethnodrama: An anthology of reality theatre. Walnut Creek, CA: AltaMira Press.

Schumacher, C. (1998). Staging the Holocaust: The Shoah in drama and performance. Cambridge, UK: Cambridge University Press.

Taylor, P. (2006). Power and privilege: Re-envisioning the qualitative research lens. In J. Ackroyd (Ed.), Research methodologies for drama education (pp. 1 - 12). Stoke on Trenk, UK: Trentham Books.

Truth and Reconciliation Commission of Canada. (2012). They came for the children: Canada, Aboriginal peoples, and residential schools. Winnipeg, MB: Author.

Truth and Reconciliation Commission of Canada. (2015a). Honouring the truth, reconciling the future-Summary of the final report of the Truth and Reconciliation of Canada. Retrieved from http: http://www.trc.ca/websites/trcinstitution/File/2015/Findings/Exec_Summary_2015_05_3 1_web_o.pdf

Truth and Reconciliation Commission of Canada. (2015b). Truth and Reconciliation Commission of Canada: Calls to action. Winnipeg, MB: Author. Retrieved from http://www.trc.ca/websites/trcinstitution/File/2015/Findings/Calls_to_Action_English2.p df

Vygotsky, L. S. (1978). Mind in society: The development of higher psychological processes (M. Cole, V. John-Steiner, S. Scribner, \& E. Souberman, Eds.). Cambridge, MA: Harvard University Press. 
Wright, D. (2007). Constructivist inquiry and learning in drama. NJ: Drama Australia Journal, 31(1), 45 - 54.

Zatzman, B. (1999). Traces of the past: Practice and research as shifting structures in drama and Holocaust education. In C. Miller \& J. Saxon, Drama and theatre in education: International conversations, (pp. 142 - 154). American Educational Research Association: Arts and Learning Special Interest Group and the International Drama in Education Research Institute.

Zatzman, B. (2005). Staging history: Aesthetics and the performance of memory. The Journal of Aesthetic Education, 39(4), 95 - 103. 


\section{Appendix A}

Questions for Focus Groups

1. a) Describe your prior knowledge or expertise that related to the development and delivery of the project?

1. b) How did you initially perceive the responsibility that you had to the school and community in the delivery of the project?

2. What inspired you to learn about the history of the Indian residential school systems?

3. What motivated you to support the concept of reconciliation of Indigenous peoples in Canada?

4. How was the topic of remembrance and reconciliation used to enhance the existing art-based course offerings while teaching the school and community about the truth of the residential school system?

5. How did using the arts as a medium strengthen the message of the project?

6. What considerations did you make throughout the development and delivery of the project so that it honoured the truths and legacy of the residential school system and its survivors?

7. a) What challenges did you encounter while addressing the sensitivity of the legacy of the residential system?

7. b) How did you overcome the challenges that you encountered?

8. Based on your experiences, what advice would you give to others who are interested in supporting situations involving remembrance and reconciliation of Indigenous peoples in Canada, or other diverse groups?

9. Is there anything else concerning your involvement in the project that I have not yet asked that you would like to provide additional information on? 